\title{
A POÉTICA DO LUTO: REFLEX̃̃O A PARTIR DO CONCEITO DE OBJETO TRANSFORMACIONAL
}

Amanda Christina Victoria de Andrade Melani

Universidade de São Paulo

Marina Ferreira da Rosa Ribeiro

Universidade de São Paulo

Janderson Farias Silvestre dos Santos

Universidade de São Paulo
Recebido em: 15/07/2020

$1^{\text {a }}$ revisão em: 14/09/2020

Aceito em: 20/11/2020

\section{RESUMO}

Partindo do conceito de objeto transformacional formulado por Christopher Bollas, discutimos o potencial transformador dos encontros estéticos. Apresentamos algumas reflexões sobre uma experiência clínica vivida com uma paciente atravessando um luto, e destacamos a marcante habilidade dela em se utilizar de músicas, imagens e metáforas para dizer de sua experiência emocional. A partir desta experiência clínica temos por objetivo, neste artigo, refletir a respeito da potência transformacional dos objetos estéticos no contexto analítico, que parecem ter um papel importante no processo de elaboração do luto desta paciente. Por fim, fazemos alguns apontamentos sobre a importância do encontro analítico, na relação de transferência-contratransferência, para o potencial de transformação dos encontros estéticos vividos nas sessões de análise.

Palavras-chave: luto; clínica psicanalítica; arte. 


\title{
THE POETICS OF MOURNING: REFLECTION FROM THE CONCEPT OF TRANSFORMATIONAL OBJECT
}

\begin{abstract}
Starting from the concept of transformational object formulated by Christopher Bollas, we discuss the transformative potential of aesthetic encounters. We present some reflections on a clinical experience lived with a patient going through mourning, and highlight her remarkable ability to use music, images and metaphors to tell about her emotional experience. Based on this clinical experience, we aim, in this article, to reflect on the transformational power of aesthetic objects in the analytical context, which seem to have an important role in the process of elaborating the mourning of this patient. Finally, we make some notes on the importance of the analytical encounter, in the transference-countertransference relationship, for the potential for transformation of the aesthetic encounters experienced in the analysis sessions.
\end{abstract}

Keywords: mourning; psychoanalytic clinic; art. 


\section{LA POÉTICA DEL DUELO: REFLEXIÓN DESDE EL CONCEPTO DE OBJETO TRANSFORMACIONAL}

\section{RESUMEN}

Partiendo del concepto de objeto transformador formulado por Christopher Bollas, discutimos el potencial transformador de los encuentros estéticos. Presentamos algunas reflexiones sobre una experiencia clínica vivida con una paciente en duelo, y destacamos su notable capacidad para usar música, imágenes y metáforas para contar su experiencia emocional. A partir de esta experiencia clínica pretendemos, en este artículo, reflexionar sobre el poder transformador de los objetos estéticos en el contexto analítico, que parecen tener un papel importante en el proceso de duelo de esta paciente. Finalmente, tomamos algunas notas sobre la importancia del encuentro analítico, en la relación transferencia-contratransferencia, para el potencial de transformación de los encuentros estéticos experimentados en las sesiones de análisis.

Palabras clave: duelo; clínica psicoanalítica; arte. 


\section{INTRODUÇÃO}

Há uma dimensão estética presente em todo encontro analítico, na medida em que o trabalho clínico se dá num campo de afetações mútuas que ocorrem primordialmente pela via sensível, antes de (e se) alcançarem o intelecto. Grande parte da potência transformacional do encontro clínico reside precisamente na disponibilidade do analista para ser afetado e, muitas vezes, perturbado pelo analisando. No entanto, no tratamento de alguns pacientes que apresentam uma relação particular com algum objeto artístico em especial, a dimensão estética do trabalho psicanalítico torna-se ainda mais evidente, já que, nestes casos, o encontro estético do paciente com o objeto transforma-se numa pauta compartilhada com o analista. É o caso da paciente que apresentamos neste artigo, que atravessava uma experiência de luto, e na qual o uso de músicas e imagens metafóricas é particularmente profícuo, abrindo ricas possibilidades de transformação.

Antes de adentrarmos na questão da elaboração do luto, apresentaremos em breves linhas o conceito de objeto transformacional, cunhado pelo psicanalista Christopher Bollas (1987/2015), conceito que servirá de base para as reflexões posteriores. Em seguida, refletiremos sobre o uso e a importância das músicas e metáforas no processo elaborativo da paciente.

Ao longo deste artigo, enfatizamos a relação da paciente com a música, a fim de mostrar a importância dos recursos artísticos na elaboração de suas experiências emocionais. Evidentemente, tratam-se de recortes do processo analítico e, ao escolher trilhar este caminho, inevitavelmente deixamos de enfatizar outros tantos aspectos do processo de atravessamento da dolorosa experiência de luto. Um destes aspectos é a própria relação de transferência-contratransferência. Assim, ao fim, faremos alguns breves assinalamentos sobre este ponto.

Visto que este artigo objetiva refletir teoricamente a respeito de um fenômeno que emergiu espontaneamente na prática clínica psicanalítica, ele se baseia no método psicanalítico, que é definido por Freud (1923/1996) como um método de tratamento e investigação, consistindo numa atitude de atenção uniformemente flutuante (por parte do analista) e associação livre (por parte do paciente). Este tipo de pesquisa implica, por parte do analista-pesquisador, "uma atitude passiva de se deixar impregnar pelo outro, tanto corporal quanto espiritualmente, para depois destilar, das marcas desse encontro os ingredientes necessários à formulação do conhecimento buscado" (Naffah Neto \& Cintra, 2012, p. 42).

Quanto aos objetivos, este trabalho pode ser definido como um estudo exploratório, na medida em que objetiva "proporcionar maior familiaridade com o problema, com vistas a torná-lo mais explícito ou a construir hipóteses" (Gehardt \& Silveira, 2009, p. 35). Nas palavras de Gil (2008): "as pesquisas exploratórias têm como principal finalidade desenvolver, esclarecer e modificar conceitos e ideias, 
tendo em vista a formulação de problemas mais precisos ou hipóteses pesquisáveis para estudos posteriores" (p. 27)

\section{O OBJETO TRANSFORMACIONAL E O MOMENTO ESTÉTICO}

O conceito de objeto transformacional, cunhado pelo psicanalista Christopher Bollas (1987/2015), descreve o objeto primário a partir de uma perspectiva intersubjetiva, enfatizando a experiência vivida pelo bebê do encontro com este objeto. Para ele, o encontro primevo do bebê com a mãe é, antes de tudo, um encontro estético, de maneira que a relação do bebê com a mãe como objeto transformacional configura a primeira estética humana. Esse encontro entre o bebê e o objeto transformacional é, para Bollas, um momento estético. A mãe é percebida no início não como um objeto de representação, mas como um processo que o bebê identifica com as múltiplas transformações do self. Nas palavras de Bollas: "A dor da fome, um momento de vazio, é transformada pelo leite da mãe em uma experiência de plenitude. Esta é uma transformação fundamental: vazio, agonia e raiva se tornam plenitude e contentamento" (p. 68). Ao longo de toda nossa vida buscamos experiências como essa, que possam nos proporcionar transformação. Procuramos mergulhar no quadro, na música, na paisagem, na voz da pessoa amada ou em seu abraço, tal como um dia estivemos mergulhados na estética materna. Os encontros estéticos são, então, encontros transformacionais.

É importante enfatizar, no entanto, que o momento estético não diz respeito a uma simples revivência da experiência com o objeto primário, como se o indivíduo estivesse fixado num encontro passado, mas sim a uma experiência com um objeto que, tal como o objeto materno, ressoa o idioma pessoal ${ }^{1}$ do indivíduo, permitindo-lhe apropriar-se de partes suas e de sua experiência emocional antes desconhecidas de si mesmo. Nas palavras de Bollas:

É um prazer da subjetividade (jouissance) descobrir os meios de ser 'sonhado' até alcançar a realidade; é uma alegria verdadeira o encontrar de um objeto que contém uma experiência que é para nós transformacional, à medida que produz uma metamorfose de uma estrutura latente profunda para uma expressão superficial (1992/1998, p. 39, itálico do autor).

O momento estético, portanto, é uma experiência que aponta para o futuro, para uma expansão e transformação da subjetividade. Este momento, segundo Bollas (1987/2015), pode ser pensado como a vivência de uma comunicação profunda e singular entre o sujeito e o objeto, em um encontro fusional que leva o indivíduo a experimentar a estranha sensação de estar sendo contido pelo objeto (como, por exemplo, um objeto artístico), que dá forma às suas angústias, desejos e medos. Assim, no encontro estético, vivenciamos uma espécie de cisão no tempo que nos arrebata e mobiliza aspectos muito íntimos, de modo a sairmos transformados deste encontro: 
No momento estético, quando uma pessoa se envolve em uma profunda ressonância subjetiva com um objeto, a cultura encarna nas artes vários equivalentes simbólicos dessa busca pela transformação. Na procura por uma profunda experiência subjetiva com um objeto, o artista nos lembra e nos fornece exemplos de experiência de memórias egóicas de transformação (Bollas, 1987/2015, p. 63-64).

Assim, nos momentos de imersão, em que o sujeito é tomado pela obra, seja ela uma pintura, uma música ou uma produção literária, por exemplo, constituem-se ocasiões de grande densidade emocional e destituídas de palavras, que, segundo Bollas, atuam como "uma forma de déjà vu, é uma memória existencial: lembrança não representacional, transmitida por meio de uma sensação misteriosa" (1987/2015, p. 67). Logo, podemos pensar o encontro estético não como uma vivência passiva, mas como uma experiência de transformação do self.

Neste artigo, tomando como ponto de partida a experiência vivida com uma paciente atravessando um luto, refletimos sobre a potência transformacional do encontro estético no contexto analítico, particularmente em pacientes que se utilizam de músicas, filmes, imagens ou metáforas, a fim de dizer de sua experiência emocional. Assim, a vinculação do sujeito a este objeto, mediada pela analista na relação transferencial-contratransferencial, pode ser experimentada como uma comunicação profunda que o leva a re-experienciar uma relação objetal transformacional, operando significativas transformações do self.

\section{O LUTO}

Adriana ${ }^{2}$ procurou a clínica-escola após a morte do marido, que ocorrera poucos meses antes do início dos atendimentos. Segundo ela, estava sendo muito difícil e doloroso aceitar essa perda, que se deu de modo inesperado em consequência de algumas complicações de saúde. Em seu relato emocionado, Adriana revelou o sentimento de não ter perdido apenas seu marido, mas também seu melhor amigo, já que estavam juntos há muitos anos e tinham um relacionamento de muita intimidade. Assim, ela diz que depois da perda o seu mundo parecia estar em "preto e branco", apontando ter uma grande dificuldade em cumprir as obrigações do dia a dia e em seu trabalho. Ela destacou também a dificuldade que sentia frente à responsabilidade de criar os filhos sozinha, um menino e uma menina iniciando a adolescência. Apesar disso, Adriana reforçava que os filhos eram sua razão para seguir em frente, de modo a trazer um pouco do colorido para os seus dias.

Nesse sentido, nas primeiras sessões, Adriana dizia se sentir deslocada, vivendo em um mundo que não parecia seu, tal como uma realidade virtual ou um sonho. Ela acrescentava ainda que se sentia incompreendida pelas pessoas que não the pareciam entender ou não estavam dispostas a ouvir sobre sua dor. Assim, a desorganização interna e externa provocada pela morte do marido fazia transparecer em sua fala uma sensação de não-pertencimento. 
É possível pensar que o caos interior decorrente da perda do marido parecia dificultar o restabelecimento de laços com o mundo externo, pois este lhe parecia hostil, tal como apontado por ela no início dos atendimentos. Assim, para além da perda concreta do objeto de amor, soma-se uma perda interior advinda da fantasia inconsciente de que o seu mundo interno parece correr perigo de desmoronar. Isto coaduna-se com a hipótese apontada por Klein (1940/1996), segundo a qual o luto é uma atualização da posição depressiva infantil, uma vez que o sujeito acredita ter perdido seus objetos internos "bons", ao mesmo tempo em que tem a impressão de que seus objetos internos "maus" se tornaram dominantes. Nas palavras de Klein (1940/1996), "assim como a criança pequena que passa pela posição depressiva está lutando, na sua mente inconsciente, para estabelecer e integrar seu mundo interno, a pessoa de luto também sofre a dor de restabelecêlo e reintegrá-lo" (p. 397).

Ao longo das primeiras sessões, as falas de Adriana eram marcadas por essa sensação de desorganização interna, ao mesmo tempo em que a sensação de incompreensão das pessoas ao seu redor, no que se referia à sua tristeza, era percebida por ela como grande hostilidade. Isto se assemelha à experiência de luto da Sr. A, descrita por Klein (1940/1996):

(...) ficou claro que a indiferença assustadora das pessoas era um reflexo de seus objetos internos, que na sua mente tinham se transformado numa multidão de objetos "maus" persecutórios. O mundo externo parecia artificial e irreal, pois a verdadeira confiança na bondade interna desaparecera temporariamente ( $p$. 404).

Embora na fala de Adriana comparecesse essa percepção hostil do mundo, era possível perceber em seu discurso a preservação de objetos internos bons, especialmente quando se referia aos filhos. Nesse sentido, é a partir deste contexto, muitas vezes ambíguo, que podemos pensar o movimento da experiência de elaboração desta paciente. Esse movimento ambíguo, com avanços e retrocessos, é próprio da experiência de luto. Mesmo no luto normal o indivíduo apresenta processos psíquicos próximos a uma experiência melancólica, engendrando uma identificação maciça com o objeto perdido, como maneira de negar a perda, de modo que há um desânimo profundamente penoso e a diminuição do interesse pelo mundo. Como observa Steiner (1994), o enlutado procura "apossar-se do objeto e retê-lo e um dos modos pelos quais o faz (...) é através da identificação com o objeto" (p. 68).

Steiner (1994) propõe dividir a posição depressiva em duas fases. A primeira seria a fase de medo da perda do objeto e a segunda a fase de reconhecimento da perda, isto é, a verdadeira vivência da experiência da perda. Essas duas fases são atualizadas nas perdas posteriores, correspondendo às fases do trabalho de luto. $\mathrm{Na}$ fase inicial o indivíduo tenta negar a realidade da perda por meio de uma 
maciça identificação projetiva, esvanecendo a separação entre sujeito e objeto e abandonando todo o tipo de interesse que não tenha relação com o objeto perdido.

Quando o indivíduo ultrapassa essa fase, podendo enfrentar a realidade, a desolação de seu mundo interno, isto é, podendo viver a experiência da perda, permitindo que o objeto morra, "a identificação projetiva é revertida e partes do self antes atribuídos ao objeto são revertidos ao ego" (Steiner, 1994, p. 68). Steiner destaca que, de certa forma, essa ideia já está presente em "Luto e melancolia", quando Freud (1917/ 1996) refere-se ao fato de que, no luto normal, o confronto com o veredicto da realidade de que o objeto não existe mais leva a um gradual desligamento da libido desse objeto e o reinvestimento em outros. Esse é um processo que proporciona um enriquecimento egóico. No luto normal, portanto, é possível a ultrapassagem do caos interior e o restabelecimento de laços com o mundo externo.

Nos relatos de sua história conjugal, Adriana compartilha com a analista experiências felizes que viveu com o marido, dizendo sentir falta de poder conversar com ele, ou apenas poder dividir os momentos do dia a dia com alguém. Contou também que costumava escutar músicas junto com o marido, porém, depois de sua morte, passou por um período em que preferiu "ficar em silêncio". Segundo ela, a música os conectava, como se os diferentes álbuns contassem partes de sua história juntos, de modo que cada canção representaria um "pedaço" deles mesmos. Assim, escutá-las novamente implicaria no reencontro com sua própria história e com a falta do marido.

Podemos conjecturar, seguindo a proposição de Steiner (1994) a respeito das duas fases da posição depressiva, que Adriana ainda estava vivendo a experiência de identificação projetiva maciça com o marido, experiência que o autor sugere que faz parte da primeira fase do luto e da posição depressiva. Deste modo, escutar sozinha as músicas que antes compartilhava com o companheiro talvez fosse confrontar-se com o vazio, enfrentar a perda, o fato de que seu parceiro não estava mais ali para viver com ela aqueles momentos de intimidade. Escutar música com o marido os conectava. Agora viver sozinha essa experiência, era dar-se conta da desconexão.

\section{A MÚSICA COMO OBJETO TRANSFORMACIONAL}

Logo nos primeiros atendimentos, alguns meses depois da perda, Adriana contou sobre o seu processo de ouvir músicas novamente. Ela relata, assim, uma sensação, em certo momento, de ser "chamada" pelos discos do marido, como se pedissem para ser ouvidos por ela. Ao se reencontrar com essas músicas, a paciente fala sobre uma experiência de identificação, em que as letras pareciam expressar com precisão os seus sentimentos frente ao luto. A partir disso, ela passa a recitar diversos versos de músicas ao longo das sessões, de modo a se comunicar por meio delas. 
Em uma das sessões, Adriana fala sobre sua experiência de solidão após a morte do marido, descrita por ela como uma sensação de estar só mesmo no meio da multidão. Neste momento, ela relembra a música "Metade" ${ }^{3}$, de Adriana Calcanhotto, e cita um dos versos, apontando se sentir "exatamente desse jeito". A paciente conta ter se identificado com o trecho "Eu não moro mais em mim", de forma que este verso parecia ser capaz de expressar sua experiência emocional, conferindo-lhe sentido. Ao se encontrar com a ideia de não morar mais em si mesma, ela revela se sentir desabitada, descrevendo uma sensação de vazio, em que não conseguia se reconhecer nela mesma, pois nada parecia ter restado de si depois da perda do marido. Retomando a proposta de Klein (1940/1996), no luto, a perda de um objeto bom externo provocaria uma fantasia inconsciente de perda dos objetos bons internos, de modo que o mundo interno do sujeito enlutado, em suas ansiedades persecutórias, pareceria correr risco de desintegração. Ao afirmar que não mora mais em si mesma, a paciente pode dizer do vazio provocado pela perda de seus objetos bons internos, que parecem não lhe fazer mais morada, após a morte de seu marido.

Expandindo a análise da música para além do trecho citado por Adriana, é possível pensar que a questão da perda parece estar muito presente e evidente, quando, no decorrer da letra, é apontada a possibilidade de perder o chão, as palavras, a hora, o freio e as chaves de casa. Deste modo, são apresentadas na música ideias cujo campo semântico é capaz de aludir tanto a uma perda concreta, tal como a perda das chaves de casa, mas que também é acompanhada pela perda de objetos internos, simbolizada, por exemplo, na ideia de perda do chão, sugerindo uma profunda desorganização do sujeito. Logo, a música como um todo parece dizer de um processo muito semelhante à experiência de luto, em que há uma profunda desorganização interna e externa com a perda do objeto de amor.

Ainda pensando no restante da letra da música em questão, os trechos "Estou em milhares de cacos" ou "Eu estou ao meio" parecem representar esses sentimentos caóticos. No luto, o indivíduo se defronta com uma nova realidade, que parece perder o sentido na ausência daquele que se foi, ao mesmo tempo em que uma espécie de caos interior se instaura. Na perspectiva trazida por Klein (1940/1996), com a perda da pessoa amada, o sujeito enlutado acredita ter perdido também seus objetos "bons" internos, e, com isso, tem a impressão de estar dominado por objetos "maus", que ameaçam a integridade do mundo interno. A ideia de um risco de desintegração parece estar contida nas imagens da música, com a possibilidade de se estar em cacos ou cindido ao meio. Assim, a partir do trecho "Onde será que você está agora?", também presente nesta música, é possível pensar na busca pelo objeto de amor perdido, durante o processo de elaboração do luto, na perspectiva de reinstalação deste objeto dentro de si. Ao mesmo tempo, este questionamento pode dizer também da procura deste sujeito por si mesmo, que depois da perda se torna um outro, transformado pela experiência.

Vale destacar também, que, na música de Calcanhotto, o trecho "Eu deixo a porta aberta" parece apresentar uma possibilidade ou abertura para a elaboração deste 
caos. Nesse contexto, é importante destacar o fato de que a paciente trouxe essa música diversas vezes para as sessões, retomando sempre o trecho "Eu não moro mais em mim". Ao fazer esta retomada, em outro momento na sua experiência de elaboração do luto, Adriana traz uma nova ideia, e aponta que sente que não mora mais em si, pois agora se percebia como outra, ou seja, sentia que não era mais a mesma, desde a perda de seu marido. A imagem trazida pela música, portanto, não dizia mais da experiência de sentir-se desabitada, mas traz a possibilidade de um (re)encontro consigo mesma, agora transformada no processo de reconstrução de seu mundo interno. Assim, Adriana tem a experiência de não morar mais em si, pois seu mundo interior, que fora destruído em sua fantasia com a perda do marido, agora pode ser restaurado pelo processo de introjeção não só do objeto de amor perdido, mas de reinstalação de todos os seus objetos "bons" internos. Logo, por meio da experiência de encontro com a música, a paciente pode pensar suas feridas e dar um passo na elaboração de sua perda.

A partir deste encontro estético, é possível pensar no caráter transformacional da música em questão. Ao escutá-la, a paciente se identifica com um dos versos, e afirma que "era exatamente isso que sentia", ou seja, diz de um encontro fusional, entre o ego e o objeto, da sensação de estar sendo contida pela letra da canção. Ao trazer este verso para a sessão, e partilhá-lo com a analista, Adriana parece experimentar uma sensação de transformação, com a mobilização de aspectos muito íntimos de sua subjetividade. Pensando no conceito de objeto transformacional, proposto por Bollas (1987/2015), o encontro estético com a música em questão parece caracterizar um processo que altera a experiência do self, transformando o mundo interno e externo da paciente.

Além disso, em outra sessão, Adriana contou que, em um determinado momento daquela semana, enquanto escutava rádio distraidamente, ouvira a música "Aonde quer que eu vá" ${ }^{4}$, cantada por Herbert Vianna. No encontro com essa música, a paciente relata uma experiência afetiva intensa, pois percebera que tinha a mesma sensação do cantor, que compôs a referida canção após a morte de sua esposa. Adriana conta que se identifica com a história do cantor, assim como se identifica com os sentimentos cantados por ele, como se Herbert fosse capaz de traduzir em palavras aspectos da sua experiência subjetiva que ela mesma não tinha sido capaz de nomear até então. Aqui também Adriana tem um verdadeiro encontro estético com essa música, na qual re-experienciaria sua relação com um objeto transformacional, a partir da fusão do ego com o objeto estético. Como proposto por Bollas, na ocasião destes momentos

É comum que o indivíduo sinta uma profunda concordância subjetiva com um objeto (uma pintura, um poema, uma melodia ou sinfonia ou uma paisagem natural) e vivencie uma fusão misteriosa com o objeto, evento que evoca outra vez um estado do ego que prevalecia na vida psíquica precoce (1987/2015, p. 52). 
Assim, Adriana cita o trecho "Aonde quer que eu vá/Levo você no olhar", e diz que sentia a presença do marido dentro de si, e não apenas nos objetos que the pertenciam. Deste modo, Adriana afirma não ser mais apenas uma pessoa, no singular, pois agora sentia que ela mesma era também o marido, levantando a possibilidade de que seu "eu" está dividido com ele. Assim, a paciente destaca o citado trecho, se referindo à ideia de uma ausência presente do marido, ou seja, da possibilidade de que ele viveria em suas lembranças e seria capaz de olhar o mundo pelos olhos dela. Logo, é possível pensar em um importante passo no processo de elaboração do luto, com introjeção do objeto de amor perdido. Segundo Klein (1940/1996):

Quando o sofrimento é vivido ao máximo e o desespero atinge seu auge, o indivíduo de luto vê brotar novamente seu amor pelo objeto. Ele sente com mais força que a vida continuará por dentro e por fora, e que o objeto amado perdido pode ser preservado em seu interior (p. 403).

Deste modo, estendendo a análise da música em questão, para além do trecho citado pela paciente, a ideia de que "Não estou ao seu lado/Mas posso sonhar", ainda presente na letra, traz a possibilidade de preservação do objeto perdido dentro de si. Assim, a morte impossibilita a presença física, mas a habilidade de sonhar permite a manutenção das lembranças do objeto de amor perdido, ao mesmo tempo em que pode pressupor uma abertura para a vivência de novas experiências. Além disso, seguindo na análise da música, no trecho "Meus sonhos vão te buscar/Volta pra mim/Vem pro meu mundo/Eu sempre vou te esperar", é reforçada a ideia de internalização do objeto, de modo que podemos pensar no "meu mundo", como o mundo interno da paciente, que passa a abrigar o marido na forma de um objeto interno "bom".

Ademais, retomando a fala de Adriana, depois de sua reflexão sobre a música, a paciente comenta que, apesar de levar a esposa no olhar, Herbert Vianna retomou sua vida e voltou a cantar e compor. A partir disso, Adriana disse ter se identificado com o cantor, pois agora também se percebia capaz de ver um futuro para si, no qual poderá voltar a criar e realizar coisas, para além de cuidar de seus filhos. Assim, a identificação com este objeto artístico parece transcender a obra, e alcançar inclusive seu autor. Encontrar-se com esta música, enquanto um objeto transformacional, parece ter tido um efeito de organização da experiência para esta paciente, oferecendo novos sentidos para a experiência traumática da perda. O seu movimento de elaboração do luto, inclusive, se torna bastante evidente quando pensamos na transformação do estilo das músicas trazidas por ela no decorrer dos atendimentos. As canções abordadas inicialmente, com letras muito intensas e tristes, foram se transformando em músicas mais leves, com palavras de esperança, acompanhando a experiência de elaboração da paciente. 
Adriana se utiliza das imagens representadas nas letras das músicas para dar sentidos a suas experiências emocionais e, ao mesmo tempo, é transformada no encontro com essas obras. Nesse contexto, sua capacidade expressiva metafórica parece ter um funcionamento semelhante. Durante as sessões, Adriana era capaz de criar imagens para expressar e dar sentido ao vivido, como forma de interpretação do mundo e de si mesma. Assim, a construção de suas metáforas se dava como uma espécie de pintura com palavras, repleta de formas, cores e profundidade, transformando sua experiência subjetiva em uma produção estética. Sua capacidade simbólica, por meio da criação de imagens metafóricas, parece dar forma para aspectos de sua subjetividade difíceis de serem representados.

Nesse sentido, em uma das sessões, Adriana disse se sentir em um quadro, em que se via equilibrando-se em uma estreita canoa, em meio às ondas de um mar azul. Segundo ela, não seria possível ver as margens, mas tinha consciência de que elas existiam, em algum lugar, mesmo que não fosse capaz de enxergá-las. Sua descrição é bastante vívida e detalhada, como se, de fato, conseguisse sentir essa experiência enquanto a descrevia. Por meio dessa imagem, a paciente consegue expressar seus sentimentos, comunicando significados e dando sentido às suas vivências. Assim, a criação e descrição dessa pintura imaginária, parece dar conta de representar os sentimentos de ambiguidade de Adriana, naquele momento de sua vida. Se, por um lado, ela se encontrava à deriva no mar, tentando equilibrarse frente aos desafios decorrentes da perda do marido, por outro, parece ser capaz de pensar na existência de margens, que dão continência para esse sofrimento, bem como dizem da possibilidade de pensar um futuro em terra firme, agora sem o seu companheiro. Essa metáfora, portanto, se mostra muito representativa de seu processo de elaboração do luto, uma vez que, apesar do momento presente de turbulência e sofrimento intenso, decorrentes de sua perda, parecia haver uma perspectiva de abertura para um segundo momento, de reconstrução, em que será possível seguir em frente.

Após um ano da perda de seu marido, a ideia de seguir em frente parecia cada vez mais presente no discurso da paciente. Ao falar sobre o seu sentimento de tristeza, Adriana citou o trecho da música "Saindo de Mim"5. "Você foi saindo de mim/Devagar e pra sempre". A partir desses versos, a paciente apontou que, tal como na ideia apresentada pela música, a tristeza da perda vai saindo dela aos poucos, abrindo espaço para novas experiências. Ao mesmo tempo, porém, ela indica que este movimento de aprender a lidar com a falta do marido acontece devagar e para sempre, assim como nos versos, por ser um processo que vivencia todos os dias, sendo alguns deles mais difíceis do que outros. Ela contou que percebe o luto como um processo que tem o seu próprio tempo, que não é linear e nem cronológico. Logo, a partir das ideias trazidas pelos versos da música citada, Adriana pôde comunicar aspectos importantes de sua subjetividade, se permitindo pensar o movimento na sua experiência de elaboração do luto.

A partir desta reflexão, Adriana disse que não entendia a sua tristeza como se fosse um baú, pesado, e impossível de carregar. Nesse sentido, ela contou que se sentia 
como uma motocicleta, capaz de seguir, percorrer caminhos e resolver problemas, e sua tristeza seria como um carrinho acoplado a esta moto, um sidecar. Adriana acrescenta, então, que uma parte da sua tristeza pelo luto talvez sempre esteja com ela, acoplada à sua motocicleta, mas o conteúdo do sidecar pode mudar com o tempo, ficar mais leve, de modo que não a impediria de seguir adiante. Assim, por meio da criação desta metáfora, Adriana constrói e apresenta uma imagem dinâmica do seu sentimento de tristeza, que se transforma com o tempo, e não mais constitui um peso que a impede de prosseguir. Sua fala, portanto, parece revelar passos muito importantes no sentido da elaboração da perda e da abertura para novas experiências, indicando o processo de transformação desta paciente em seu trabalho de luto. O discurso de Adriana parecia estar preenchido de novas cores e possibilidades, muito diferente de sua fala nas primeiras sessões, que era marcada pela sensação dilacerante de desorganização interna e deslocamento em relação ao mundo. Assim, a metáfora construída pela paciente parece indicar sua transformação no processo de reconstrução de seu mundo interno, com uma abertura para seguir adiante, como proposto por ela.

Enquanto a paciente construía esta metáfora, a palavra sidecar parecia ecoar de modo insistente pela mente da analista, provocando uma sensação de estranhamento. Nesse momento, ela tenta se lembrar de onde conhecia este termo, e imediatamente pensa em uma cena do livro "Harry Potter e as relíquias da morte" ${ }^{\prime \prime}$. Nela, Harry é transportado no sidecar de uma motocicleta, em um plano de fuga que dá início a sua jornada final contra o vilão Lord Voldemort. Durante essa fuga, a coruja de Harry, símbolo de sua inocência e de sua ligação com o mundo mágico conhecido até então, é morta dentro do sidecar. Assim, mais do que apenas derrotar o vilão, a história nos leva a pensar sobre o amadurecimento de Harry, que se encontra com o desconhecido, enfrenta seus medos e luta bravamente por seus ideais. Nada mais será como antes, e após a batalha, surge um novo Harry, transformado pela experiência.

A imagem que surge na mente da analista, em sua ressonância contratransferencial, e as reflexões propostas a partir dela, parecem se relacionar com a história da paciente. Na metáfora criada por Adriana, a ideia de seguir adiante, de percorrer novos caminhos, parece indicar que, aos poucos, ela estaria se desocupando da realidade que construíra com o marido, de modo a partir para uma nova jornada de (re)descoberta de si mesma. Esta jornada não é fácil, assim como as batalhas enfrentadas por Harry, mas uma nova Adriana parece surgir desta experiência de elaboração.

Bollas (1987/2015) afirma que muitas vezes o analista capta em sua própria subjetividade estados emocionais do paciente em statu nascendi. O autor chega a afirmar que frequentemente o processo de associação livre se dá dentro do analista, de maneira que este deve encontrar maneiras de relatar ao paciente seus processos internos, para "ligar o paciente a algo que ele tenha perdido em si mesmo" (p. 236). Deste modo, diz o autor: 
(...) os pacientes se beneficiam do enraizamento responsável e confortável do analista na experiência subjetiva. A avaliação do que é verdadeiro no paciente não brota inevitavelmente de uma seleção intelectualizada de temas inconscientes, lida pelo paciente e pelo analista, mas sim de um sentimento mútuo de ter tocado em um detalhe na sessão que dá a ambos uma sensação de convicção apropriada de que o self verdadeiro do paciente foi encontrado e registrado (p. 240-241).

Desta forma, à medida que a analista permite-se ser habitada pelos estados emocionais da analisanda, ela pode sonhar o vivido, por meio de fenômenos estéticos, como as referidas associações com o Harry Potter, de maneira que tanto a analista quanto a paciente podem encontrar sentidos para a experiência compartilhada em sessão. A capacidade de metaforização dessa paciente permite transformar experiências emocionais em imagem, ao mesmo tempo em que a imagem criada pela analista parece ser capaz de captar significados que circulavam na fala de Adriana.

Os objetos estéticos, portanto, parecem ter um papel importante no processo de elaboração do luto desta paciente, auxiliando a expressão e a organização de suas experiências emocionais e conferindo novos sentidos ao vivido. Adriana relata a experiência de uma relação muito íntima com as músicas e metáforas trazidas ao longo das sessões, de modo a experimentar a sensação de estar sendo contida por estes objetos. Logo, é possível pensar esses elementos enquanto objetos transformacionais, que possibilitam experiências de transformação do self (Bollas, 1987/2015). Como proposto por Figueiredo (2014), o sujeito entrega-se a esses objetos, para deles receber cuidados, experimentando seus efeitos de sustentação, continência e reconhecimento. Para o autor, a busca por equivalentes simbólicos para o objeto transformacional seria uma busca por cuidados, na qual o self "ora cria, ora descobre, ora recria objetos sob medida para suas necessidades de constituição, reconstituição e reparação narcísica" (p. 79). Experiência essa muito semelhante a que pode ser observada na relação de Adriana com as músicas.

Ademais, o luto, enquanto uma experiência de alta densidade emocional, parece conter em si um potencial criativo. Assim, a dor da perda, que desorienta, que afoga, que dilacera, consegue encontrar voz na arte, que oferece meios para expressar o inominável, aquilo que escapa à razão. Por meio de objetos estéticos, esta dor pode ser pintada, nas diferentes cores da tristeza e da saudade, de modo a dar forma para os mares tempestuosos que podem tomar conta do mundo interno do sujeito enlutado. Assim, por meio de músicas e metáforas, Adriana pode contar, e de certo modo cantar, sua própria história, abrindo a possibilidade de transferir-se para essas obras, levando consigo suas memórias, medos, angústias e representações, de modo a nelas se deixar transformar.

Logo, a capacidade de metaforização e de articulação de elementos simbólicos, tão marcante nesta paciente, promove uma abertura para sonhar o vivido, para 
organizar e refletir sobre sua experiência, na busca de sentido e elaboração para o seu sofrimento. Nesse caso, a elaboração implica encontrar novos sentidos para a vida, agora sem a pessoa que se foi, ou seja, diz da capacidade de pensar uma vida possível após a perda.

\section{O ENCONTRO ANALÍTICO COMO ENCONTRO ESTÉTICO}

As músicas e metáforas trazidas pela paciente foram viabilizadas no campo analítico, em um espaço potencial habitado por ela e pela analista. Deste modo, o processo de transformação não se dá apenas no simples encontro com os objetos estéticos, mas também na oportunidade de falar e refletir sobre eles, endereçandoos a uma presença disponível e continente. O potencial transformador não está apenas no objeto estético, mas também no encontro transferencialcontratransferencial. Assim, Adriana pôde encontrar um lugar de pouso para dar voz e espaço à sua dor, a fim de então pensar suas feridas por meio da linguagem poética.

A importância do encontro intersubjetivo para a realização do potencial transformador do encontro estético é enfatizado por Safra (1999), segundo o qual o fenômeno estético só acontece quando uma presença humana devolve ao sujeito a melodia que outrora era emitida "para o espaço sem fim" (p. 35), pois de certo modo é somente neste momento que o sujeito pode ter um contato pessoal, subjetivado, com a realidade.

Utilizamos acima a palavra melodia, fazendo referência a uma experiência clínica de Safra (1999). Aqui fazemos uso do termo como metáfora para qualquer aspecto do idioma pessoal do indivíduo, não apenas aquelas ligadas à musicalidade. Safra descreve a experiência com um menino, a quem ele dá o nome de Ricardo, que poderia ser diagnosticado como autista, com o qual somente após anos de análise foi possível estabelecer uma verdadeira comunicação a partir de uma melodia que o pequeno paciente entoava e que Safra começa a repetir. Nesse momento, pela primeira vez o menino o olha nos olhos, bate palmas e emite outra melodia para que Safra repetisse. O autor afirma: "Devolvi-Ihe a melodia e, em resposta, ele pulou alegremente pela sala, criou uma outra melodia, e o jogo se repetiu. Estávamos nos comunicando!" (p. 34). No caso de Adriana, as melodias também constituem parte importante de seu idioma.

Podemos dizer que o processo de transformação de Adriana se dá não apenas na projeção de partes suas no outro (o objeto artístico-musical), mas também na retomada das partes projetadas, com o auxílio da analista. Quando a analista pôde ressoar o idioma de Adriana, posto nas músicas que ela trazia, então ela pôde encontrar a si mesma nas músicas, reintegrar partes que haviam se perdido junto com o marido, e poder sonhar. Nas palavras de Cintra (2011): "deixar passar o passado e poder sonhar, eis dois critérios freudianos de saúde mental" (p. 5). Esse é, de fato, o percurso realizado por Adriana em seu atravessamento do luto. 
Segundo Bollas (1987/2015), a mãe atua como um ego suplementar, que permite a continuidade de ser do infante, dando forma a seu mundo interno. Assim, ao satisfazer as necessidades do bebê, ela transformaria seu ambiente exterior e interior, ou seja, a mãe, ainda não identificada como um outro, diferente do eu, é experienciada como um processo de transformação, como um objeto transformacional. Bollas (1987/2015) afirma que, de modo semelhante, o analista deve funcionar como objeto transformacional, na medida em que ele deve executar com o paciente

(...) a mesma função da mãe com seu bebê, que não podia falar, mas cujos humores, gestos e necessidades eram expressões de algum tipo que precisavam da percepção materna (...), do acolhimento (uma disposição para lidar com o discurso infantil), da transformação em alguma forma de representação e possivelmente, de alguma solução (o fim do sofrimento) (p.264, itálicos nossos).

Bollas (1987/2015) afirma que cada paciente cria um ambiente a partir de seu idioma, de maneira que o analista é convocado a viver dentro do idioma ambiental do paciente. A este respeito é interessante observar que as músicas citadas e cantadas por Adriana, tão características de seu idioma, pareciam ecoar ao longo das sessões, de modo que suas melodias se mantinham como uma espécie de ruído de fundo nos encontros, habitando a mente da analista.

No idioma ambiental do analisando somos usados por ele de modos diferentes e, muitas vezes, não sabemos porque sentimos o que sentimos e mesmo que papel somos destinados a desempenhar. Haveria, em todo processo analítico uma "incerteza inevitável, sempre presente e necessária" (Bollas, 1987/2015, p. 234) Nesse sentido, é emblemático certo momento no decurso do processo analítico de Adriana em que ao fim de uma sessão, ao se despedir, ela comenta não saber o que a analista fazia com todo o "lixo" deixado ali, mas agradecia por recolhê-lo para ela, deixando seu sidecar mais leve. Este comentário é representativo do uso que Adriana faz da analista em seu idioma ambiental e da inevitável e necessária incerteza do processo, pois muitas vezes a analista também não sabe o papel que desempenha e o que faz com o que é "depositado" pelo paciente:

A capacidade de suportar e valorizar esta necessária incerteza define uma de nossas mais importantes responsabilidades clínicas com o paciente; e aumenta nossa capacidade de nos perdermos no ambiente em evolução do paciente, possibilitando que ele nos manipule pelo uso da transferência, transformandonos em uma identidade objetal. Se estivermos seguros de nosso próprio senso de identidade, perdê-lo no espaço clínico é essencial para a descoberta que o paciente faz de si mesmo ( $p$. 234). 
Na medida em que a analista pôde suportar a experiência de incerteza, ela pôde partilhar a dor, vivida em uníssono, e lançar-se com Adriana nas incertezas das águas do luto, navegadas por meio de músicas e metáforas que parecem funcionar como uma espécie de gramática afetiva para esta paciente, ou, como diria Bollas (1992/1998), como um léxico para o processamento das experiências do self. Assim, é por meio dessas construções estéticas que os sentimentos de Adriana podem ser expressos, ao mesmo tempo em que parecem constituir uma forma de elaboração de sua experiência. Nesse sentido, o luto ganha vida por meio da linguagem poética, criando a possibilidade de delinear novas formas e contornos para a dor.

Dentro do contexto de intimidade do setting analítico, as experiências emocionais turbulentas podem ser apreendidas e expressas por meio das imagens criadas pela dupla analítica. Deste modo, o vivido ganha forma, a partir da qual pode ser digerido e transformado em uma narrativa elaborada, e geradora de novos sentidos. A imersão no contato com os objetos estéticos em sessão se dá, então, como uma experiência compartilhada. Assim, é no encontro de subjetividades da sala de análise que a experiência pode ser sonhada em conjunto, favorecendo o processo de transformação.

\section{CONSIDERAÇÕES FINAIS}

A experiência com Adriana permitiu-nos refletir sobre as possibilidades transformacionais dos encontros estéticos tanto no uso das músicas quanto na relação analítica. Pudemos pensar, então, os encontros estéticos no contexto analítico em seu potencial transformacional. Ao cantar e construir imagens metafóricas, compartilhando essa experiência com a analista, ela parece encontrar um lugar de abrigo e cuidado. Assim, Adriana pode habitar e ser habitada por esses objetos. Nas palavras de Figueiredo (2014), "É 'de dentro' que o sujeito pode vir a sofrer todos os efeitos deste encontro" (p. 79). Nesta experiência clínica, acompanhamos os efeitos do encontro com as músicas e com a analista, e destacamos a importância da habilidade da paciente de articular elementos estéticos, dando formas e encontrando sentidos para suas experiências emocionais.

Para finalizar, assinalamos que além de refletir sobre a potência transformacional das músicas para a paciente, é importante enfatizar o quanto as canções tão caras para Adriana, servem elas mesmas como um tipo de representação plástica da teoria do luto, compreendida na perspectiva das relações de objeto, bem como como representação da dor e da travessia do luto feita pela paciente. Por fim, as músicas também indicaram novos sentidos (ou uma expansão de sentidos) para a analista. 


\section{REFERÊNCIAS}

Bollas, C. (2015). A sombra do objeto São Paulo, SP: Escuta. (Trabalho original publicado em 1987).

Bollas, C. (1998). Sendo um personagem. Rio de Janeiro, RJ: Revinter (Trabalho original publicado em 1992).

Cintra, E. (2011). Sobre luto e melancolia: Uma reflexão sobre o purificar e o destruir. ALTER - Revista de Estudos Psicanalíticos, 29(1), 23-40.

Figueiredo, L. C. (2014). Cuidado, saúde e cultura - Trabalhos psíquicos e criatividade na situação de analisante. São Paulo, SP: Escuta.

Freud, S. (1996). Luto e melancolia. In Freud, S. A história do movimento psicanalítico, artigos sobre metapsicologia e outros trabalhos (pp. 245-265. Vol. XIV; Edição Standard Brasileira das Obras Psicológicas Completas de S. Freud). Rio de Janeiro, RJ: Imago. (Trabalho original publicado em 1917).

Freud, S. (1996). O ego e o id. In Freud, S. O ego e o id e outros trabalhos (pp. 15-87. Vol. XIX; Edição Standard Brasileira das Obras Psicológicas Completas de S. Freud). Rio de Janeiro, RJ: Imago. (Trabalho original publicado em 1923).

Gehrardt, T. E., \& Silveira, D. T. (2009). Métodos de pesquisa. Porto Alegre, RS: Editora da UFRGS.

Gil, A. C. (2008). Métodos e técnicas de pesquisa social. São Paulo, SP: Atlas. (Trabalho original publicado em 1999).

Klein, M. (1996). O luto e suas relações com os estados maníaco-depressivos. In Klein, M. Amor, culpa e reparação e outros trabalhos (pp. 385-412, Vol. I, Obras completas de Melanie Klein). Rio de Janeiro, RJ: Imago. (Trabalho original publicado em 1940).

Naffah Neto, A., \& Cintra, E. M. U. (2012). A pesquisa psicanalítica: A arte de lidar com o paradoxo. ALTER - Revista de Estudos Psicanalíticos, 30(1), 33-50.

Safra, G. (1999). A face estética do self. São Paulo, SP: Unimarco.

Steiner, J. (1994). O equilíbrio entre as posições esquizo-paranóide e depressiva. In Anderson, R. (Org.). Conferências clínicas sobre Klein e Bion (pp. 60-72). Rio de Janeiro, RJ: Imago.

\section{CONFLITOS DE INTERESSES}

Não há conflitos de interesses.

\section{SOBRE OS AUTORES}

Amanda Christina Victoria de Andrade Melani é graduanda em Psicologia no Instituto de psicologia da USP. Membro do Laboratório Interinstitucional de Estudos da Intersubjetividade e Psicanálise Contemporânea (LIPSIC).

E-mail: amanda.melani@usp.br

(iD https://orcid.org/0000-0003-2449-3420

Marina Ferreira da Rosa Ribeiro é psicanalista. Professora Dra. do Programa de Pós-graduação em Psicologia Clínica do Instituto de Psicologia da USP. Coordenadora do Laboratório Interinstitucional de Estudos da Intersubjetividade e Psicanálise Contemporânea (LIPSIC).

E-mail: marinaribeiro@usp.br

iD https://orcid.org/0000-0002-1601-4744

Janderson Farias Silvestre dos Santos é psicólogo. Doutorando e mestre em Psicologia Clínica pelo Instituto de Psicologia da USP, na linha de pesquisa "Investigações em Psicanálise". Membro do Laboratório Interinstitucional de Estudos da Intersubjetividade e Psicanálise Contemporânea (LIPSIC). E-mail: jandersonsilvestre@usp.br 


\begin{abstract}
${ }^{1}$ Podemos pensar no idioma como uma forma primordial, como um traço formal primevo que só pode se articular e se fazer expressar pela recepção de conteúdos do mundo externo que são continuamente oferecidos, inicialmente, pelas figuras parentais. Bollas relaciona o idioma ao Id dizendo: "A teoria do id foi um primeiro e crucial passo para conceituar essa importante estrutura psíquica (itness), algo próprio que está no nosso cerne, algo que dirige a consciência: uma figuração da personalidade que conjura objetos específicos para desfazer seu código por tais objetivações. Acima de tudo nossa itness, ou nosso idioma pessoal é o nosso mistério. Nós pensamos, sonhamos, abstraímos, selecionamos objetos antes de sabermos por que e mesmo quando sabemos tão pouco" (Bollas, 1992/1998, p. 37).

${ }^{2}$ Nome fictício. Destacamos aqui que a escolha do nome Adriana faz referência à cantora Adriana Calcanhotto, que dá voz à música "Metade". O verso desta canção, tão fundamental para a experiência de elaboração desta paciente, parece ser capaz representá-la. Assim, a Adriana, paciente, no encontro com as palavras de Adriana, cantora, pode dizer de sua experiência emocional.

${ }^{3}$ Calcanhotto, A. (1994). Metade [CD Recording]. Sony Music.
\end{abstract}

Eu perco o chão

Eu não acho as palavras

Eu ando tão triste

Eu ando pela sala

Eu perco a hora

Eu chego no fim

Eu deixo a porta aberta

Eu não moro mais em mim

Eu perco as chaves de casa

Eu perco o freio

Estou em milhares de cacos

Eu estou ao meio

Onde será

Que você está agora?

${ }^{4}$ Vianna, H. (2000). Aonde quer que eu vá [CD Recording]. EMI.

Olhos fechados

Pra te encontrar

Não estou ao seu lado

Mas posso sonhar

Aonde quer que eu vá

Levo você no olhar

Aonde quer que eu vá

Aonde quer que eu vá

Não sei bem certo

Se é só ilusão

Se é você já perto

Se é intuição

E aonde quer que eu vá

Levo você no olhar

Aonde quer que eu vá

Aonde quer que eu vá

Longe daqui

Longe de tudo

Meus sonhos vão te buscar

Volta pra mim

Vem pro meu mundo

Eu sempre vou te esperar

Larará! Lararára!

${ }^{5}$ Lins, I. (1979). Saindo de mim [LP]. EMI.

Você foi saindo de mim

Com palavras tão leves

De uma forma tão branda 
De quem partiu alegre

Você foi saindo de mim

Com sorriso impune

Como se toda faca não tivesse

Dois gumes

Você foi saindo de mim

Devagar e pra sempre

De uma forma sincera

Definitivamente

Você foi saindo de mim

Por todos os meus poros

E ainda está saindo

Nas vezes em que choro

${ }^{6}$ Rowling J. K. (2007). Harry Potter e as relíquias da morte. São Paulo, SP: Rocco. 